\title{
A case of Advanced Gastric cancer patient treated by Korean Medicine monotherapy
}

\author{
Sulki Kim ${ }^{1}$, Changgue Son ${ }^{1}$, Inwoo Choi ${ }^{2}$, Sojung Park ${ }^{1 *}$ \\ ${ }^{1}$ Dept. of East-West Cancer center, Department of Internal Medicine, Dunsan Korean Medicine Hospital of \\ Daejeon University, \\ ${ }^{2}$ Department of Internal Medicine, Dunsan Oriental Hospital of Daejeon University
}

\begin{abstract}
Objectives: The present study reports case of an advanced gastric cancer patient who did not receive resection and was treated with Korean Medicine (KM) monotherapy.

Methods: A 59-year-old female patient diagnosed with advanced gastric cancer visited the Dunsan Korean medicine Hospital of Daejeon University on April 15, 2018 for the Korean medicine treatment. The patient was treated with KM for approximately 1 year, from May, 2018 to May, 2019. Computed tomography (CT) was used to follow-up of the tumor site. Laboratory analysis and National Cancer Institute Common Terminology Criteria for Adverse Event (NCI-CTCAE), version 5.0 were used to evaluate the safety of our treatment.

Results: The patient's quality of life (QOL) and related symptoms improved during the treatment.

Conclusion: This study suggests that KM may help to improve QOL of advanced gastric cancer patients. This is a valuable report that shows the natural history of Korean gastric cancer invasion to deeper layers over time.
\end{abstract}

$\overline{\text { Key Words }}$ : Advanced gastric cancer, Korean medicine, acupuncture, Samchilchoongcho-Jung, Geonchil-Jung, Gongjin-Dan

\section{Introduction}

After thyroid cancer, gastric cancer is the most common carcinoma for both genders combined as of 2016. Gastric cancer occurs in 35.4 cases per 100,000 people, and the prevalence rate is $273,701^{1)}$. The prognosis of gastric cancer is divided into Early Gastric Cancer (EGC) and Advanced Gastric Cancer (AGC) according to the invasion of the mucous membrane. EGC has a 5 -year survival rate of $90 \%$; however, AGC has a poor prognosis with a high relapse rate of $79 \%$ within 2 years and a median survival of less than 12 months after relapse ${ }^{2,3)}$. The general treatment for gastric cancer is radical resection, which involves surgical removal of the part or all of the lesion and lymph nodes. After surgery, adjuvant chemotherapy, immunotherapy, and radiotherapy should be performed in consideration of the patient's condition. However, major side effects of surgery include symptoms of digestive and absorption disorders, such as dumping syndrome,

\footnotetext{
- Received : 25 October 2019

- Revised : 18 November 2019

- Accepted : 20 November 2019

- Correspondence to : Sojung Park

Dept. of East-West Cancer center, Department of Internal Medicine, Dunsan Korean Medicine Hospital of Daejeon University

75, Daedeok-daero 176beon-gil, Seo-gu, Daejeon, Republic of Korea

Tel : +82-42-470-9134, Fax : +82-42-470-9008, E-mail : vivies@dju.ac.kr
} 
gastric acid reflux, and anemia. Other side effects of chemotherapy include nausea, vomiting, hair loss, decreased immunity, numbness of the hands and feet, fatigue, and weight loss, all of which can cause a deterioration of patients' quality of life $^{2)}$. These side effects usually last about six months after chemotherapy and can last longer depending on the individual's social and biological environment ${ }^{4}$. With a gradual increase of the incidence and survival rates of gastric cancer, there is a growing awareness that social and psychological problems of gastric cancer patients should be considered. The quality of life itself is suggested as the sole criterion for evaluating the effectiveness of treatment ${ }^{5}$.

This case is a report of a female patient who progressed to AGC after being diagnosed with EGC and who did not receive special treatment for 3 years due to side effects of surgery and chemotherapy. The patient only received KM monotherapy, improved cancer-related symptoms, and continued to have excellent quality of life during the course of treatment

\section{Report of the case}

Patient consent and Dunsan Oriental Hospital of Daejeon University Institutional Review Board (IRB) deliberation (DJDSKH-19-E-07-1) were obtained for the case study.

\section{Patient characteristics and medical history}

A 59-year-old woman diagnosed with EGC (adenocarcinoma, moderately differentiated) at Korean Health Examination Center on January 22, 2015 was recommended to address a higher-level hospital. She visited $\bigcirc \bigcirc$ University hospital, but was refused to get surgery and chemotherapy due to the side effects. She only received symptomatic treatment. On December 27, 2017, the patient visited the emergency department of $\bigcirc \bigcirc$ University hospital with the complaints of melena, palpitation, and weakness. Gastrointestinal bleeding was also found, and the patient received cauterization, recommended for gastrectomy. The patient also refused surgery and was discharged from the hospital. On June 2, 2018, melena recurred. After an emergency department visit at $\bigcirc \bigcirc$ University hospital, gastrointestinal endoscopic cauterization was performed, and the patient diagnosed with an AGC-Borrmann type 3, which means progression of malignant neoplasm. The patient had no previous history of alcohol of drug abuse or smoking, and had no specific family and past history.

\section{Diagnosis and treatment}

The patient was medium build with the body mass index 22.83, height $148 \mathrm{~cm}$, and body weight $50 \mathrm{~kg}$. She complained of chest discomfort (painful esophagus with a blocked esophagus along the sternum), and dyspepsia (bloating at xiphoid process after meal), weakness, and anorexia. Her diet consisted of a diet for cancer patients, and she ate 3 meals a day, 1 bowl per meal. She had a banana- sized stool three times a day, and slept 4-5 hours per day shallowly. Her tongue texture was pale red and dry with thick and white fur, and the pulse was fine and faint. Accordingly, the symptom differentiation was diagnosed as “Deficiency of Qi and blood (氣血兩 虚)”

Periodic KM monotherapy was continued for one year with two weeks of in-patient treatment every month over twelve times from June 11, 
2018, to May 28, 2019. In terms of herbal medicine, we prescribed Gongjin-Dan (供辰丹) (GJD) once before breakfast, Samchilchoongcho-Jung (三七蟲草錠) (SCCCJ) three times after meal, and Geonchil-Jung (乾漆錠) (GCJ) three times after meal per day. The Prescription and Compositional Volume of Drugs are summarized in Table 1. Acupuncture was performed twice daily (morning and afternoon) mainly at 合谷(LI14), 衝陽(ST42), 足三里(ST36)，上巨虛(ST37)，下巨虛(ST39)，神門 (HT7), 太谿(KI3). Needles were made of stainless steel needles $(0.20 \times 30 \mathrm{~mm}$, DongBang Co. Seoul, Korea), and immersion was carried out for 15 minutes at the depth of $10 \mathrm{~mm}$. Moxibustion treatment was performed twice a day for 30 minutes. Moxibustion was performed once in the both core of palms and foot, or once in the umbilicus. Dry cupping therapy was performed on the shoulder and back once a day for 5 minutes.

\section{Evaluation Method}

1) Computed tomography $(\mathrm{CT})$ results

On August 4, 2018, an abdominal CT scan showed a $4 \times 2.5 \times 1.5 \mathrm{~cm}$ tumor in the upper part of the stomach. On February 13, 2019, abdominal CT scan showed a $5 \times 3 \times 1.7 \mathrm{~cm}$ tumor, i.e. increased by $21 \%$ from the previous size and measured by progressive disease (PD) stage based on Response Evaluation Criteria in Solid Tumors
(RECIST). The abdominal CT on April 152019 was measured at the same size as before and was measured as a stable disease (SD) stage based on RECIST $^{6}$ (see Figure 1)

2) Clinical pathology test result

During the treatment, hepatic function level such as Aspartate aminotransferase (AST), Alanine aminotransferase (ALT), Gamma Glutamyl Transpeptidase ( $\gamma$-GTP), and renal function level such as Blood urea nitrogen (BUN), Creatinine were maintained in the normal range. There was a decrease in Red Blood Cell (RBC) at admission in June 2018, but RBC has continued to rise since then. There was no increase in inflammation-related levels such as White Blood Cell (WBC) during the treatment. In addition, Carcinoembryonic Antigen (CEA), Carbohydrate Antigen 19-9 (CA19-9), a tumor marker of gastric cancer, remained within the normal range (see Table 2).

\section{3) Body weight}

At admission on June 11, 2018, the patient weighed $49.8 \mathrm{~kg}$, and since then she recorded the maximum of $51.6 \mathrm{~kg}$ (December 12, 2018) and the minimum of $48.3 \mathrm{~kg}$ (April 23, 2019). Body weight remained constant.

4) Numeral Rating Scale (NRS) and Eastern

Table 1. Prescription and Compositional Volume of Drugs

\begin{tabular}{|c|c|}
\hline Prescription & Compositional Volume of Drugs(mg) \\
\hline $\begin{array}{l}\text { Gongjin-Dan } \\
\text { (供辰丹) }\end{array}$ & Cervi Parvum(73.4), Angelica Gigas Root(73.4), Cornus Fruit(73.4), Musk(80) \\
\hline $\begin{array}{l}\text { Samchilchoongcho-Jung } \\
\text { (三七蟲草錠) }\end{array}$ & $\begin{array}{l}\text { Radix Panax notoginseng }(81) \text {, Cordyceps militaris(61.5), Panax ginseng C.A. Meyer(61.5), Boswellia } \\
\text { carterii BIRDWOOD }(46)\end{array}$ \\
\hline $\begin{array}{l}\text { Geonchil-Jung } \\
\text { (乾漆錠) }\end{array}$ & Allergen-removed Rhus Vernicflua Stokes(60) \\
\hline
\end{tabular}



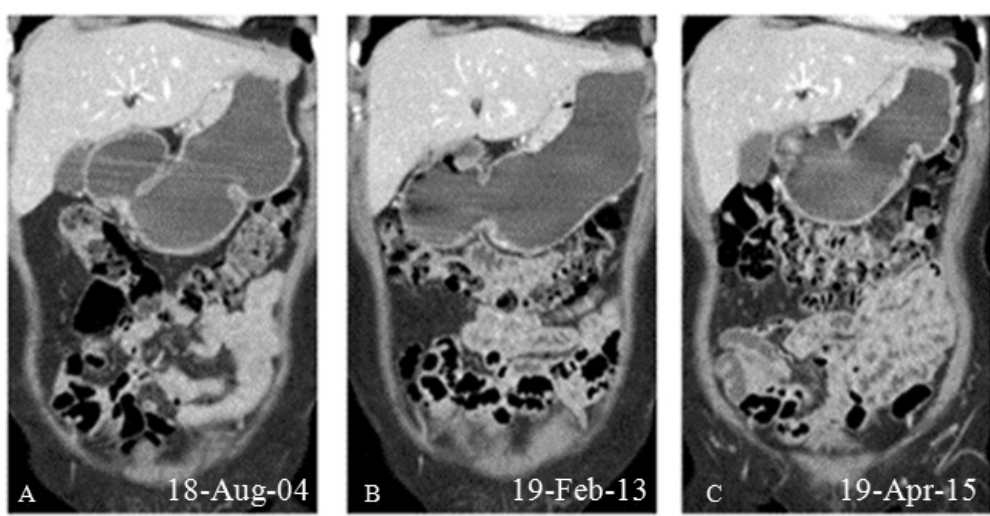

Fig. 1. Abdominal Computed Tomography

A: Known stomach cancer; lesser curvature side of upper body; $4 \times 2.5 \times 1.5 \mathrm{~cm}$ size

B: Known stomach cancer; lesser curvature side of upper body; $5 \times 3 \times 1.7 \mathrm{~cm}$ size (increase mass size)

C Known stomach cancer; lesser curvature side of upper body; $5 \times 3 \times 1.7 \mathrm{~cm}$ size (no interval change of mass size)

Cooperative Oncology Group performance status (ECOG PS) grade

Fatigue and dyspepsia decreased from NRS9 and NRS6 to NRS3 at discharge in June 2018, and remained at NRS 1-4 afterwards.

During one year of treatment, the patient maintained ECOG PS grade 1 (restricted in physically strenuous activity, but ambulatory and able to carry out work of a light or sedentary nature - for example, light house work, office work) and continued her activities both socially and economically by keeping a steady job before the onset (see Figure 2).

\section{Discussion and Conclusion}

From 2011 to 2016, the incidence rate of gastric cancer in Korea has decreased by $5.4 \%$

Table 2. Laboratory findings

\begin{tabular}{|c|c|c|c|}
\hline Laboratory findings & 2018-06-11 & 2019-02-12 & 2019-05-16 \\
\hline $\mathrm{WBC}\left(10^{3} \mathrm{~mm}^{3}\right)$ & 7.7 & 7 & 6.8 \\
\hline $\operatorname{RBC}\left(10^{6} \mathrm{~mm}^{3}\right)$ & 3.70 & 3.82 & 4.02 \\
\hline Hemoglobin(g/dl) & 10.1 & 10.7 & 11.6 \\
\hline AST(U/l ) & 21 & 16 & 19 \\
\hline ALT(U/l) & 13 & 13 & 13 \\
\hline$\gamma-\mathrm{GTP}(\mathrm{U} / \ell)$ & 33 & 27 & 36 \\
\hline Creatinine $(\mathrm{mg} / \mathrm{d} \ell)$ & 0.74 & 0.61 & 0.7 \\
\hline BUN(mg/d $\ell)$ & 11.8 & 12.2 & 14.2 \\
\hline CEA(ng/ml) & 2.43 & 1.24 & 1.8 \\
\hline CA19-9(ng/ml) & 26.24 & 21.51 & 26.21 \\
\hline
\end{tabular}

WBC, white blood cell; RBC, red blood cell; AST, Aspartate aminotransferase

ALT, Alanine aminotransferase; $\gamma$-GTP, Gamma Glutamyl Transpeptidase

BUN, Blood Urea Nitrogen; CEA, Carcinoembryonic Antigen; CA19-9, Carbohydrate Antigen 19-9 


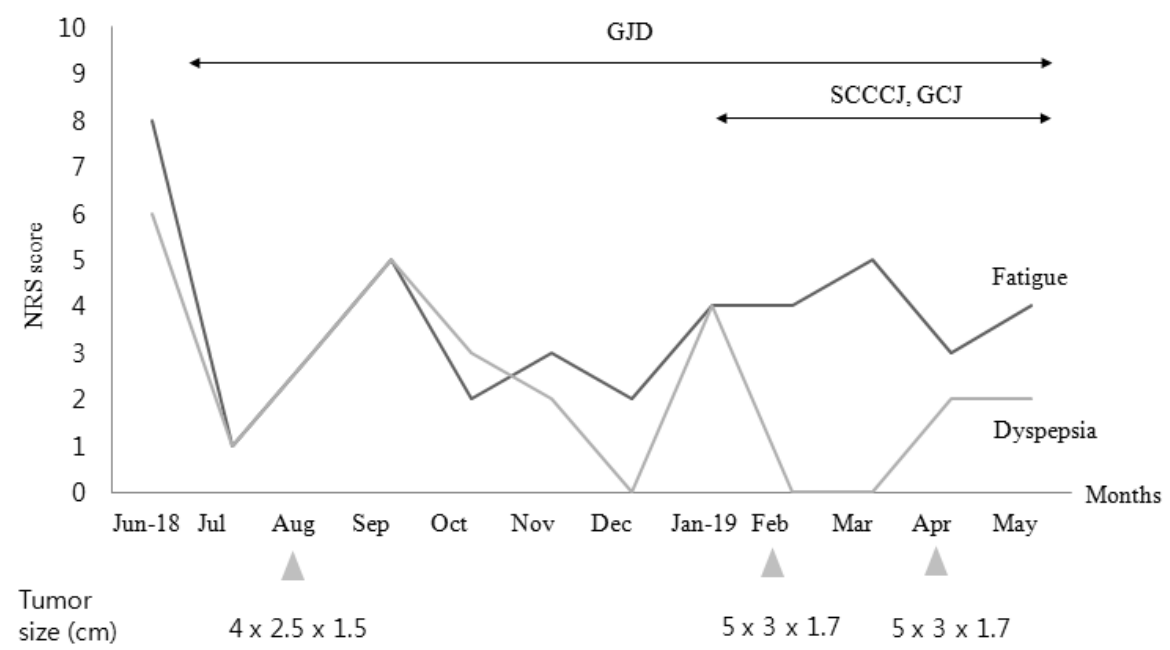

Fig. 2. Summary of Clinical outcome and treatment course

every year, and the survival rate has been gradually increasing due to the development of early diagnosis and treatment methods. Of all carcinomas diagnosed in 2016, the prevalence of gastric cancer was $23 \%$ in males and $9.5 \%$ in females ${ }^{1)}$. According to the National Comprehensive Cancer Network (NCCN)'s guidelines, resection is performed when possible. Combination therapy with 5-fluorouracil (5-FU) and cisplatin is recommended as the first-choice therapy ${ }^{3}$. However, in the case of resection, dumping syndrome which includes diarrhea, nausea, abdominal pain, and heartburn may appear as side effects after surgery. 5-FU or cisplatin can cause dermatitis when contacted with drugs and intravenous phlebitis when intravenous injection. Furthermore, bone marrow suppression, digestive symptoms such as nausea, dyspepsia, and diarrhea can considerably reduce patients' QOL. Oral medications, as such as Gemcitabin and S-1, have been developed to improve this problem; however, side effects such as hand-foot syndrome, i.e. the loss of hand and feet skin, infections caused by bone marrow suppression, and hair loss, still remain a challenge.

In the reported case, the patient was a 59-year-old woman who was diagnosed with EGC in January 2015 and refused treatment due to the side effects of resection and chemotherapy. In 2017 and 2018, melena was caused by gastrointestinal bleeding due to a gastric malignant neoplasm. At the time of the second endoscopic cauterization, malignant neoplasm was diagnosed to have progressed to Borrmann type 3 due to the invasion of the adrenal muscle layer. Since then, the patient visited a Korean medicine hospital to receive treatment and received 12 single hospitalizations from June 11, 2018 to May 28, 2019 (164 days of hospitalization in total). In KM monotherapy, GJD was prescribed to improve the fatigue. Acupuncture was performed twice a day to improved blood circulation and improve symptoms. During the treatment, CT findings on February 13, 2019, showed PD, but the patient's dyspepsia were improved from NRS 7 to NRS 1, and fatigue also improved. Therefore, we decided 
to continue the then-current treatment and additionally prescribed the anticancer drug SCCCJ and GCJ. CT findings on April 15, 2019 showed SD findings, and the patient was still alive in October 2019.

There were no side effects when evaluated with NCI-CTCAE version 5.0 during the one-year treatment of Korean medicine monotherapy ${ }^{7}$. In June 2018, the results of a blood test showed that the decrease in RBC was caused by GI bleeding, after which there was no melena, and other tests showed normal range. In addition, AST, ALT, $\gamma$ -GTP, BUN, and creatinine levels remained normal, indicating no hepatotoxicity or renal toxicity during treatment. The patient also maintained normal social activities, including performing her original professional occupation during treatment.

$G J D$ has been reported to have effects on acute fatigue and persistent fatigue caused by sleep deprivation $^{8)}$. SCCCJ is a capsule containing panax notoginseng, panax ginseng, cordyceps militaris, and boswellia carterii. Park et al. reported anticancer effects of panax notoginseng on gastric cancer cell AGS and its stereospecific pharmacological activity in ovalbumin-induced inflammation. Accordingly, panax notoginseg has antioxidant effects by lowering the concentration of free radicals in cells and effect on the immune system $^{9}$. Kang et al. reported that panax ginseng enhances phagocytosis of macrophages, NK-cell function, promotes secretion of $\mathrm{TNF}-\alpha$, and IL-1â, IL-12, dendritic cells, and induces antibody formation responses against $\operatorname{IgM}, \operatorname{IgG}$, and $\operatorname{IgA}$ 10). Jian et al. reported that cordyceps militaris was effective in inhibiting the proliferation of cancer cells in gastric cancer cell SGC-7901, which caused cell death in so that the cell cycle stayed at $\mathrm{G} 2 / \mathrm{M}^{11)}$. Zhang et al. reported that boswellia carterii is involved in the $\mathrm{Wnt} / \beta$ -catenin signaling pathway and induces apoptosis through caspase-9, caspase-3, PARP, Bax/Bcl-2 ${ }^{12}$. $G C J$ is a lyophilized powder of allergen-removed Rhus Vernicflua Stokes extract (aRVS). Choi et al. reported that butein, an active ingredient of Rhus Vernicflua Stokes extract (RVS), inhibited cytokine-induced nitric oxide production and showed anti-inflammatory effects in NF-kappa B pathway. Fisetin, another active ingredient of RVS, has anti-inflammatory effects by inhibiting inflammatory cytokines such as TNF- $\alpha$, IL-6, IL- ${ }^{13)}$. In addition, RVS glycoproteins are helpful in resolving immune disorders by inhibiting T-helper type 2 (Th2) cytokines such as IL-4 and IL-10. In clinical trials, Lee et al. reported that malignant neoplasms were reduced in size after 5 months after aRVS alone in an 82-year-old gastric cancer patient ${ }^{14)}$. Acupuncture for the improvement of symptoms in cancer patients is being actively studied worldwide. For instance, Charlotte et al. reported that acupuncture is effective for pain control, anorexia, constipation, and fatigue. A review of available studies on the use of acupuncture for tumors published worldwide showed that $63 \%$ of the studies reported positive results for acupuncture ${ }^{15,16)}$.

In this case, GJD, SCCCJ, and GCJ improved symptoms of the patient whose symptom differentiation was diagnosed as "Deficiency of $Q i$ and blood (氣血兩歔)" using a combination of attack and supplement treatment(攻補兼施. In the classic works of Oriental medicine, cancer is expressed as 痕, 積 and it is interpreted as excess in symptoms; however, in reality, it is a deficiency disease (標實本虚). The patient was easily fatigued, and her tongue was pale red, pulse was 
fine and faint, meaning that she was of the deficiency pattern (虚證). However, qi stagnation (氣滞) symptoms such as the stiffness of the sternum and frequent dyspepsia and Stagnation of cold-dampness(寒濕停滞) such as her tongue with thick and white fur meant the excess pattern (實 證). Therefore, the basis of her disease was deficiency patterns, but her symptoms were excess patterns. On drug treatment, Rhus Vernicflua Stokes of GCJ and Panax notoginseng, Boswellia carterii of SCCCJ were used to promote blood circulation and remove blood stasis(活血社疼) drug, as well as to eliminate the pathogenic factor for excess patterns. Panax ginseng and GJD reinforced the healthy $q i$ (扶正) so that the patient can fulfill the deficiency. On acupuncture treatment, we mainly took the following acupunctures; LII4 (合谷), which has the effect of regulating $Q i$ (氣) and activating blood (理氣活血), unblocking the meridian collateral (通經活絡), regulating stomach and intestines, clearing heat and releasing exterior (清熱解表). ST42 (衝陽), which has the effect of relaxing sinews and activating collaterals (舒筋活 絡), tranquilizing (安神), dispersing wind-heat of head and facial part (疏散頭面風熱). We also used ST36 (足三里), which has the effect of reinforcing the healthy $q i$ (扶正), boosting $q i$ and nourishing blood (益氣養血), tonifying the spleen and stomach (建脾胃), and diffusing and unblocking $q i$ movement (宣通氣機). ST37 (上巨虚) has the effect of regulating intestines, relaxing sinews and activating collaterals (舒筋活絡). ST39 (下E虚), which harmonizes the stomach and intestines (利 腸和胃), frees the collateral vessels, and relieves pain (通絡止痛). We also used HT7 (神門), which has the effect of tranquilizing (安神寧志), harmonizing qi counter-flow (調氣遡). KI3 (太貕), which has the effect of tonifying the kidney yin
(滋㹂陰), removing deficiency heat (退虚知 ${ }^{17}$ ). Therefore, these drugs and acupuncture treatments may have helped to prevent the growth of malignant neoplasm and relieved the symptoms related to malignant neoplasm, such as fatigue and dyspepsia.

Until now, the combination therapy of chemotherapy and Korean medical treatments has been actively studied for reducing the size of malignant neoplasms and improving symptoms. In comparison, studies on the cases without surgical intervention were insignificant. In 2000, the natural course of gastric cancer without surgery was observed in 56 cases in Japan, and in 1 case in 2012 and 2016 respectively ${ }^{18-20)}$. In Korea, one case was diagnosed with AGC in 2003, but the patient showed spontaneous cure after four years without treatment. There was also a case diagnosed with gastric adenocarcinoma in 1999 and repeated spontaneous cure and recurrence with conservative treatment for 13 years. There was also a patient diagnosed with gastric cancer in 2006 who refused surgery and only took aRVS 5 months; this case showed a decreased malignant neoplasm size and survived until July $2011^{14,21 \text {, }}$ 22).

In a study by Tomorino et $\mathrm{al}^{19)}$, an 85 -year-old woman was diagnosed with EGC in $6 \mathrm{~mm}$ of malignant tumors in the lower third of her stomach in 2007. However, the patient hoped for conservative treatment because of rheumatoid arthritis and ischemic heart disease. The size of the tumor as maintained until 2009, but in 2010 and 2011, the size gradually increased to $12 \mathrm{~mm}$ and invaded the mucous membrane. In May 2012, the tumor went became deeper and invaded the intrinsic myocardium, and, in November 2012, it increased to $50 \mathrm{~mm}$, and the patient died of 
bleeding in 2013 with anemia and anorexia symptoms. In a study by Junko ${ }^{20)}$, an 89-year-old man was diagnosed with EGC in 1999 with a 20 $\mathrm{mm}$ malignancy on the front of the upper stomach. However, the patient has been periodic follow-up without intensive treatment because of his old age and state of inserting pace maker. Malignant neoplasm remained at $20 \mathrm{~mm}$ until 2002. However, afterwards, there has been a continuous expansion of the neoplasm's width and depth. In 2005, it invaded the intrinsic fascia, was measured $40 \mathrm{~mm}$ in 2006, $60 \mathrm{~mm}$ in 2007, and the patient died of heart failure.

Putting together the studies reviewed above, the median period of growth from EGC to AGC without treatment is 44 months; the median survival time after diagnosis of EGC is 72 months; and the 5-year survival rate is $67.8 \%$. In addition, the growth of tumor accelerates when malignant neoplasm begins submucosal invasion. In the study of Tomorino ${ }^{19}$, the tumor size more than doubled in 12 months after submucosal invasion. In the study of Junko ${ }^{20)}$, after the invasion of mucous membrane, tumor grew by 25 $\%$ in the first year, $60 \%$ in the second year, and $60 \%$ in the third year. This patient was also diagnosed as EGC, but received no treatment and developed to AGC 42 months later. In the following six months, tumor size increased by $21 \%$; however, in the subsequent two months, tumor size did not increase, resulting in only $21 \%$ growth in tumor size for 12 months. This patient progressed to AGC at 42 months, which is earlier than the median progression 44 months. Therefore, the growth rate was expected to be rapid after submucosal invasion, but the tumor increased only $21 \%$ by $\mathrm{KM}$ monotherapy, and the tumor stopped growing. Therefore, the results of the present report are meaningful in that they demonstrate that KM monotherapy can suppress tumor growth, while maintaining body weight and social functioning of the patient. Our results also contribute to the body of work on the natural history of gastric cancer. However, there are only two cases to be compared with. Therefore, more comparisons would be needed in further research. Another limitation of the present report is a short period of one year, which requires a continuous follow-up. Finally, an endoscopic confirmation is needed for bleeding from the malignant neoplasm in the stomach.

\section{Acknowledgements}

This study was supported by a grant from National Research Foundation of Korea (NRF -2018R1C1B6007898), Republic of Korea.

\section{Reference}

1. National Cancer Information Center. Cancer to see with statistics. Available from : URL: https://www.cancer.go.kr/lay1/S1T639C640/co ntents.do

2. Lee JH, Kim JG, Jung HK, Kim JH, Jeong WK, Jeon TJ et al. Synopsis on Clinical Practice Guideline of Gastric Cancer in Korea: An Evidence-Based Approach. Korean Journal of Gastroenterology. 2014;63(2):66-81.

3. Park SH, Lee SI. Recent Advances in Chemotherapy of Gastric Cancer. The Korean Journal of Medicine. 2012;82(4):417-426.

4. Kim JH, Choi JY. Postoperative Changes in Body Weight, Anxiety, Depression, and Quality of Life after Radical Gastrectomy among Patients with Gastric Cancer. Korean Oncology 
Nursing Society. 2014;14(3):139-145.

5. Park SH, Cho MS, Kim YS, Hong J, Nam E, Park J, et al. Self-reported health-related quality of life predicts survival for patients with advanced gastric cancer treated with first-line chemotherapy. Quality of Life Research. 2008;17(7):1043-4.

6. Eisenhauer EA, Therasse $\mathrm{P}$, Bogaerts J, Schwartz LH, sargent D, Ford R. New response evaluation criteria in solid tumors: Revised RECIST guideline(version1.1). European journal of cancer. 2009;45:228-247.

7. National Cancer Institue, Common Terminology Criteria for Adverse Events(CTCAE) v.5.0,2017. Available from : URL: https://evs.nci.nih.gov/ ftp1/CTCAE/CTCAE_5.0/

8. Son MJ, Im $\mathrm{HJ}, \mathrm{Ku} \mathrm{BC}$, Lee JW, Jung SY, Kim YE, et al. An Herbal Drug, Gongjin-dan, Ameliorates Acute Fatigue Caused by Short-Term Sleep-Deprivation: A Randomized, Double-Blinded, Placebo-Controlled, Crossover Clinical Trial. Frontiers in Pharmacology. 2018;9,479.

9. Park EH, Kim YJ, Noriko Y, Park SH, Kim HK, Jang HJ, et al. Stereospecific anticancer effects of ginsenoside $\mathrm{Rg} 3$ epimers isolated from heat-processed American ginseng on human gastric cancer cell. Journal of Ginseng Research. 2014;38:22-27.

10. Kang SW, Min HY. Ginseng, the 'immunity Boost':The Effect of Panax ginseng on Immune System. Journal of Ginseng Research. 2012;36(4) 354-368.

11. Xiao JH, Chen DX, Fang N, Liu ZL, Zhang T. Growth arrest of human gastric adenocarcinoma cells by bioactive compounds of Cordyceps jiangxiensis(CaoMuWang) through induction of apoptosis. Journal of Food, Agriculture\&
Environment. 2006;4:66-73.

12.Zhang YS, XIe JZ, Zhong JL, Li YY, Wang RQ, Qin YZ, et al. Acetyl-11-keto- $\beta$-boswellic acid (AKBA) inhibits human gastric carcinoma growth through modulation of the $\mathrm{Wnt} / \beta$ -catenin signaling pathway. Biochimica et Biophysica Acta. 2013;1830(6):3604-3615.

13. Choi WC, Jung HS, Kim KS, Lee SK, Yoon SW, Park JH, et al. Rhus verniciflua Stokes against Advanced Cancer: A Perspective from the Korean Integrative Cancer Center. Journal of Biomedicine and Biotechnology. 2012;874276. Available from: URL: https://www.hindawi. com/journals/bmri/2012/874276/

14. Lee SH, Choi WC, Kim KS, Park JW, Lee $\mathrm{SH}$, Yoon SW. Shrinkage of Gastric cancer in an elderly Patient Who Received Rhus verniciflua Strokes Extract. The Journal of Alternative and Complementary Medicine. 2010;16(4):497-500.

15. Charlotte H Y Lau, Edwin P Hui, Alexander Y L Lau. Acupuncture and Related Therapies for Symptom Management in Palliative Cancer Care: Systematic Review and Meta -Analysis: Erratum. Medicine(Baltimore). 2016;95(20):e $90 \mathrm{e} 6$.

16. Choi JE, Cho CK, Lee YW, Yoo HS, Lu Weidong, Elizabeth DC, et al. The Value of Acupuncture in Cancer Care. Journal of Korean Traditional Oncology. 2010;15(1), 1-17.

17. National Institute of Oriental Medicine Co-author, Meridian and Acupointology. $6^{\text {th }}$ ed. Daejeon: Jonglyeonamu; 2012, p.64, 214, 231, 236, 247.

18. Tsukuma H, Oshima A, Narahara H, Morii T. Natural history of early gastric cancer: a non-concurrent, long term, follow up study. 
Gut. 2000;47:618-621.

19. Tomohiro I, Masao Y, Hiroyuki O, Naomi K, Kohei T, Masaki T, et al. Natural History of Early Gastric Cancer: a Case Report and Literature Review. Journal of Gastric Cancer. 2017;17(1):88-92.

20. Junko F, Toshifusa N, Toshiaki H, Yorimasa Y, Akiyoshi I, Tomohiro T, et al. Natural history of gastric cancer-a case followed up for eight years: early to advanced gastric cancer. Clinical Journal of Gastroenterology. 2012;5:351-354.

21. Chung HW, Son DK, Ji JS, Chung DY, Chung JS, Kim JI, et al. A case of Spontaneous Regression of Advanced Gastric Cancer. Journal of Korean Gastrointestinal
Endoscopy. 2013;27:216-219.

22. Yang SE, Lee YJ, Lee JA, Kim SH, Jung SH, Kim anna, et al. A Patient with Distinct Evidences of Spontaneous Regression and Recurrence of Gastric Cancer for 13 Years. Journal of Korean Gastrointestinal Endoscopy. 2012;16(3):149-152.

\section{ORCID}

Sulki Kim https://orcid.org/0000-0001-5981-7849

Changgue Son https://orcid.org/0000-0001-7500-9833

Inwoo Choi https://orcid.org/0000-0002-6963-5229

Sojung Park https://orcid.org/0000-0002-7546-4091 